\title{
Solar Electric Propulsion Concepts for Human Space Exploration
}

\author{
Carolyn R. Mercer, ${ }^{1}$ Melissa L. McGuire, ${ }^{2}$ Steven R. Oleson, ${ }^{3}$ and Michael J. Barrett ${ }^{4}$ \\ NASA Glenn Research Center, Cleveland, Ohio, 44135
}

\begin{abstract}
Advances in solar array and electric thruster technologies now offer the promise of new, very capable space transportation systems that will allow us to cost effectively explore the solar system. NASA has developed numerous solar electric propulsion spacecraft concepts with power levels ranging from tens to hundreds of kilowatts for robotic and piloted missions to asteroids and Mars. This paper describes nine electric and hybrid solar electric/chemical propulsion concepts developed over the last 5 years and discusses how they might be used for human exploration of the inner solar system.
\end{abstract}

\section{Introduction}

$\mathrm{N}$ ASA is developing a strategy to send crew to Mars in the 2030s. To achieve this goal, NASA plans to develop the technology needed for long-duration space flight, including advanced transportation systems and the systems needed to work and live in deep space. Among these technologies, solar electric propulsion (SEP) has been identified as enabling for efficiently moving large masses through interplanetary space. ${ }^{1,2}$ For decades it has been known that missions beyond low Earth orbit (LEO) could be cost-effectively accomplished by using high-power SEP, yet until recently, flight missions had not materialized, in part because the component technologies were not sufficiently mature. ${ }^{3}$ NASA's recent investment in solar arrays and electric thruster systems has matured them such that 50-kW-class SEP systems are now ready to be infused into flight missions. We have also analytically demonstrated that these technologies could be scaled to system power levels of several hundreds of kilowatts. $^{3,4}$

These technologies are expected to be demonstrated on missions increasingly distant from Earth to build confidence before we embark on missions that are truly independent of Earth. The missions will advance human exploration capability from our current Earth-dependent phase, through a proving ground that demonstrates longduration survival in cislunar space, to Earth independence at Mars and its environs. ${ }^{5}$

To help both guide the needed technology development and envision how the technologies could scale to enable future capabilities, the NASA Glenn Research Center has conducted numerous concept studies showing how SEP systems might be configured to explore near-Earth asteroids (NEAs) and Mars, using SEP to carry both crew and cargo. These destinations were chosen as representative of proving-ground and Earth-independent targets, and some of the concepts were developed with and for NASA's Evolvable Mars Campaign. We developed three types of concepts: "SEP-only," which would employ only SEP-propelled spacecraft to conduct a mission; SEP-powered spacecraft as part of a "split architecture," which would employ SEP to transport cargo but chemically propelled spacecraft to transport crew; and hybrid SEP and chemical propulsion spacecraft (SEP-Chem), which would combine electric thrusters and chemical rockets in a single spacecraft. The concepts all assumed that there would be either a single dedicated launch for the spacecraft, or a dual manifest with cargo to be directly delivered or prepositioned for subsequent docking. Piloted missions assumed a rendezvous in LEO or cislunar space, and some missions relied on in-space refueling.

This paper describes eight recent studies that show how flexible-blanket solar arrays and Hall effect thruster (HET) systems could be configured and scaled up to accomplish increasingly more capable missions. Each of these is in support of human exploration missions to NEAs and the Mars environment. For SEP concepts applicable to science missions see Refs. 6 and 7. For SEP concepts applicable to lunar missions, see Ref. 8. The missions and the technologies that form the building blocks of each of these nine concepts are described, together with the expected

\footnotetext{
${ }^{1}$ Project Manager, Space Technology Project Office, 21000 Brookpark Road/MS 162-8, AIAA Member.

${ }^{2}$ Aerospace Engineer, Mission Architecture \& Analysis Branch, 21000 Brookpark Road/MS 162-2, AIAA Member. ${ }^{3}$ Aerospace Engineer, Mission Architecture \& Analysis Branch, 21000 Brookpark Road/MS 162-2, AIAA Member. ${ }^{4}$ Deputy Chief, Space Technology Project Office, 21000 Brookpark Road/MS 162-8, AIAA Member.
} 
use of SEP and chemical systems and missions of interest in the proving-ground and Earth-independent phases of exploration. The methodology used to conduct the studies is explained, followed by a description of each of the concepts. The concept descriptions include the spacecraft configuration, capability, mission, and any notable variants.

\section{Mission Concepts and Critical Solar Electric Propulsion Components}

The vehicle concepts described in Section IV were developed to illustrate how missions to NEAs and the Mars environment might be executed using SEP to substantially reduce propellant mass, and hence cost, relative to chemical propulsion. This suite of concepts began in 2010 with the initiation of NASA's "flexible path" approach to technology development ${ }^{9,10}$ and has served to guide the development of the key technologies needed to enable these vehicles as well as guide mission-planning efforts. Each concept was developed by Glenn's Collaborative Modeling for Parametric Assessment of Space Systems (COMPASS) team over a 2-week period, with sufficient fidelity to reasonably conclude that the missions were feasible with the nominal configuration. Design trades between power and propulsion technologies were then used to identify parameters that could make the most significant impact on system performance (e.g., bus voltage and thruster power level), and those insights were used to develop solar arrays, electric thrusters, and power processing unit (PPU) engineering development hardware that now enable highpower SEP flight missions.

Our concepts use SEP in three primary ways: (1) alone- to transport both cargo and crew, (2) to transport cargo as part of a split architecture that employs chemically propelled spacecraft to transport crew, and (3) in a hybrid SEP-Chem spacecraft that uses chemical propulsion in the gravity wells near Mars and Earth and uses SEP to spiral out of Earth's orbit, if needed, and for interplanetary propulsion. This classification is summarized in Table 1.

Table 1. Summary of solar electric propulsion concepts

\begin{tabular}{|c|c|c|c|c|c|c|c|c|c|}
\hline & \multicolumn{6}{|c|}{ Pure SEP Spacecraft } & \multicolumn{3}{|c|}{ Hybrid SEP-Chem Spacecraft } \\
\hline Where described & IV.A & IV.B & IV.C & IV.D & IV.E & IV.F & V.A & V.B & V.C \\
\hline Mission & $\begin{array}{l}\text { Robotic } \\
\text { Mars }\end{array}$ & $\begin{array}{l}\text { Robotic } \\
\text { NEA }\end{array}$ & $\begin{array}{c}\text { Cargo to } \\
\text { Mars } \\
\text { vicinity }\end{array}$ & $\begin{array}{c}\text { Cargo to } \\
\text { Mars } \\
\text { vicinity }\end{array}$ & $\begin{array}{l}\text { Crew to } \\
\text { NEA }\end{array}$ & $\begin{array}{l}\text { Cargo to } \\
\text { Mars }\end{array}$ & $\begin{array}{l}\text { Robotic } \\
\text { Mars orbit }\end{array}$ & Crew to Mars & Crew to Mars \\
\hline $\begin{array}{l}\text { Solar power at end of } \\
\text { life }\end{array}$ & $25 \mathrm{~kW}$ & $40 \mathrm{~kW}$ & $150 \mathrm{~kW}$ & $150 \mathrm{~kW}$ & $300 \mathrm{~kW}$ & $440 \mathrm{~kW}$ & $25 \mathrm{~kW}$ & $320 \mathrm{~kW}$ & $800 \mathrm{~kW}$ \\
\hline $\begin{array}{l}\text { Part of split } \\
\text { architecture? }\end{array}$ & & & $\checkmark$ & $\checkmark$ & & $\checkmark$ & & & \\
\hline $\begin{array}{l}\text { Study year } \\
\text { [Reference] }\end{array}$ & 2015 & $\begin{array}{c}\text { 2012-2015 } \\
\text { [Refs. 20, 21] }\end{array}$ & $\begin{array}{c}2015 \\
\text { [Ref. 23] }\end{array}$ & 2015 & $\begin{array}{c}2011 \\
\text { [Ref. 25] }\end{array}$ & 2014 & 2015 & $\begin{array}{c}2015 \\
\text { [Ref. 27] }\end{array}$ & $\begin{array}{c}2012 \\
\text { [Ref. 29] }\end{array}$ \\
\hline
\end{tabular}

\section{A. Mission Concepts}

NASA's journey to Mars could include missions to asteroids and Phobos as shown in Figure 1. A full capability Mars mission was described in NASA's 2009 Design Reference Architecture (DRA) 5.0, including trajectory options for mission opportunities spanning the 15-year synodic cycle and architectures using both nuclear thermal and chemical systems for in-space transportation. ${ }^{11}$ Key assumptions included (1) the use of a heavy-lift launch vehicle with shroud dimensions ranging from 8.4 to $12 \mathrm{~m}$ in diameter and 12 to $35 \mathrm{~m}$ in length, lifting $120 \mathrm{t}$ to a 407-km circular orbit; (2) Mars insertion into a 1-sol period (250 by $33793 \mathrm{~km}$ ); (3) the transport of six crew and an Orion vehicle; and (4) conjunction-class (long-stay) missions to minimize the total required transit energy. Three crewed missions were envisioned, spanning 10 years from the first predeployed asset launch to the final crew return. Required cargo payloads included a 40-t deep space transit habitation system, a 67-t lander/ascent vehicle delivering $40 \mathrm{t}$ to the surface, and a 10-t Orion capsule to support six astronauts. DRA 5.0 can be considered the "Cadillac" of Mars exploration, using either nuclear thermal or chemical propulsion to transport cargo and providing sufficient resources for 18 astronauts to investigate three locations. The hybrid SEP-Chem concept described in Section V.C was designed to replicate this mission. Studies are underway to investigate how the payloads could be broken down into smaller packages, enabling lower power and lower cost transportation. The hybrid SEP-Chem concept described in Section V.B addresses one such scenario.

Mars' moons provide another interesting destination, without requiring landing and ascent stages. The crew could rendezvous directly with Phobos or Deimos or transit from a Mars orbit via a "Mars taxi" to demonstrate mobility, prospecting, and science capabilities. ${ }^{5}$ The SEP concepts described in Sections IV.C and V.A are intended for cargo transport in the vicinity of Mars, including Phobos and Deimos. 


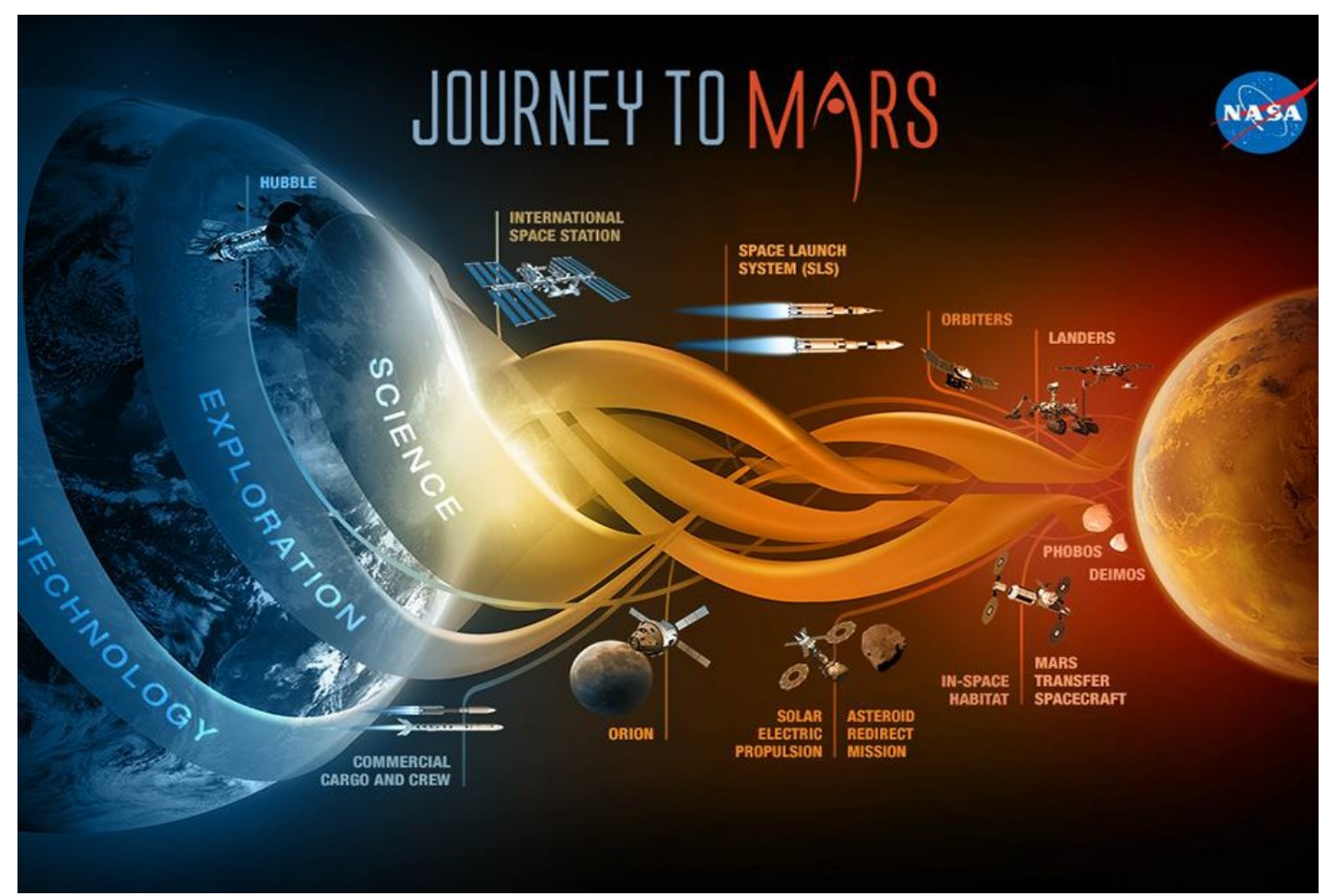

Figure 1. NASA’s journey to Mars includes missions to Mars, Phobos, and near-Earth asteroids.

In addition to the Mars environment, the exploration of NEAs both robotically and with crew is of significant interest. NASA's proposed Asteroid Redirect Robotic Mission (ARRM) would robotically demonstrate planetary defense technology and bring asteroidal mass to a lunar orbit for human examination and manipulation. Just as significantly, it would demonstrate the operation of an SEP system that is much more powerful than any flown to date and that could be scaled up significantly for the SEP systems that will be needed to deliver cargo and crew for the human exploration of Mars. ${ }^{12}$ Crew also could be sent directly to an NEO for in situ investigations on the entire body. ${ }^{13}$ The concepts described in Sections IV.B and IV.D cover these missions.

We adopted a building-block approach to developing the SEP concepts for these missions because we recognize the importance of each mission laying the ground work for subsequent missions, leading to an economical transportation system for human exploration of the inner solar system. It is also important to show how lower power missions can provide intrinsic value, as well as providing the building blocks for the future. Sections IV.A and V.A show how relatively low power SEP and hybrid SEP-Chem systems could be used to conduct robotic Mars missions.

\section{B. Solar Electric Propulsion Components}

NASA's Space Technology Mission Directorate recently developed two technologies that are critical to highpower SEP systems: (1) flexible blanket solar arrays and (2) magnetically shielded HET systems. Both technologies were built and tested to demonstrate readiness for use in a nominally 50-kW SEP system. A key feature of the solar arrays is their low mass and stowed volume at this power level, and a key feature of the thrusters is their ability to process a large quantity of propellant with low degradation for high-delta- $\mathrm{V}(\Delta \mathrm{V})$ missions. Both technologies could be scaled up to much higher power levels. All of the SEP concepts described in this paper use variations of these technologies.

\section{Flexible Blanket Solar Arrays}

The solar arrays are based on novel structures that provide a large deployed solar collection area with a small stowed volume. To accomplish this, they use tensioned mesh backplanes rather than rigid composite panels to reduce both mass and stowed volume. Two solar arrays were designed and built: (1) a rectangular roll-out design called the Roll-Out Solar Array (ROSA) from Deployable Space Systems and (2) a circular fan-fold design called MegaFlex from Orbital ATK. ROSA is deployed via a damped release of stowed strain energy in rolled slit-tube composite booms that extend a photovoltaic blanket attached to a rod connecting the outer tips of the two booms. 
MegaFlex is deployed via a motor-driven tape that first extends a hinged boom and then rotates a pivot panel through $360^{\circ}$ to unfold a photovoltaic blanket attached to radial spars for support. The boom increases the radius of the deployed circular array without increasing the length of the stowed array.

Engineering development units (EDUs) of each design were built, sized to produce nominally $20 \mathrm{~kW}$ of power using standard triple-junction (TJ) photovoltaic (PV) cells. Figure 2 shows these EDUs deployed and off-loaded in the configuration used for thermal vacuum system deployment testing. Acoustic vibration and shake tests were done with live PV cells to determine launch survivability. Deployment tests were done in vacuum at $\pm 60{ }^{\circ} \mathrm{C}$ to demonstrate autonomous deployment in a relevant environment, deployed strength and stiffness tests were done to show $0.1 \mathrm{~g}$ and first-mode $0.1-\mathrm{Hz}$ compliance, and dynamic events during deployment were assessed to understand possible failure modes. ${ }^{14}$ In addition, PV coupons were tested in the environment of an HET exhaust plume to determine safe operation up to $300 \mathrm{~V}$. These tests convinced us that both designs are ready for incorporation into a flight mission requiring nominally $40 \mathrm{~kW}$ of solar power, and analysis showed that nominally $50-\mathrm{kW}$ designs are equally feasible.
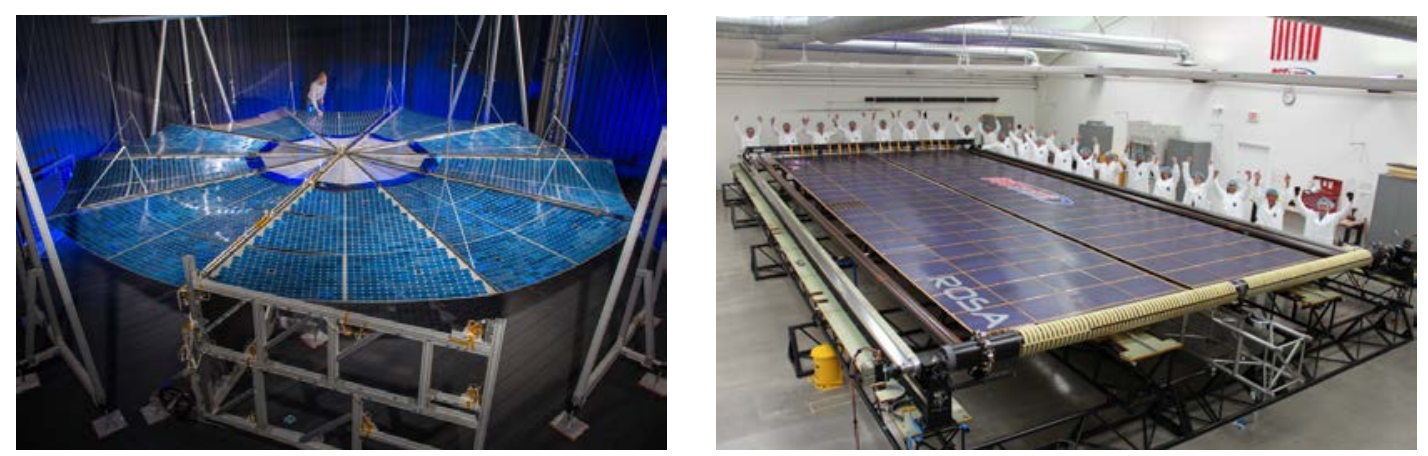

Figure 2. 20-kW-class engineering development units of Orbital Mega-Flex (left) and Deployable Space Systems ROSA (right) solar arrays.

In addition to these tests, analyses were done to determine the feasibility of scaling these solar arrays up to $125 \mathrm{~kW}$ per wing. The MegaFlex concept could be scaled up by increasing the diameter of the array and the number of spars. Analyses showed that two 30 -m-diameter wings could provide $440 \mathrm{~kW}$ of power using inverted metamorphic multijunction (IMM) PV cells and still fit within ground test chambers and stow into an 8.4- by 25-m launch shroud. The ROSA concept could be scaled up by ganging multiple winglets onto a hinged truss: that is, mounting four 25-kW ROSA arrays onto a backbone, two to a side, would form a Mega-ROSA wing producing a $100 \mathrm{~kW}$ of power. Deployable Space Systems built a demonstration backbone of this size and tested its deployment at $\pm 60{ }^{\circ} \mathrm{C}$, demonstrating feasibility. ${ }^{15}$ Increasing the number of winglets to six per wing would increase the total power of two wings to $300 \mathrm{~kW}$.

\section{Magnetically Shielded Hall Thrusters}

The electric thrusters are based on a unique magnetically shielded magnetic field topology that prevents material erosion by using a monolithic discharge chamber, a centrally mounted cathode, and a reverse-flow propellant manifold with highly uniform flow and protection from backsputtered material deposition. This low-erosion design was chosen to achieve a very high xenon propellant throughput while operating at $12.5 \mathrm{~kW}$ with a high specific impulse ( $\left.\mathrm{I}_{\mathrm{sp}}\right)$ and high efficiency. Two EDUs were designed and built: one for characterization testing and the other for environmental testing (Fig. 3).

Functional testing confirmed that the thruster's magnetic circuitry was shielded with the required field strength to prevent erosion, within allowable electromagnet current limits. Hot-fire tests confirmed the absence of voltage breakdowns during operation. Characterization testing measured surface erosion and the distribution of the near-field plasma, and it generated data for high- $\mathrm{I}_{\mathrm{sp}}$ and high thrust-to-power performance tables. Erosion rates of the discharge channel walls and magnetic circuit components were measured and found to be consistent with predicted values. Environmental testing including random vibration and thermal vacuum tests confirmed that the thruster meets the structural and thermal design specifications expected for a 50-kW SEP mission. ${ }^{17}$

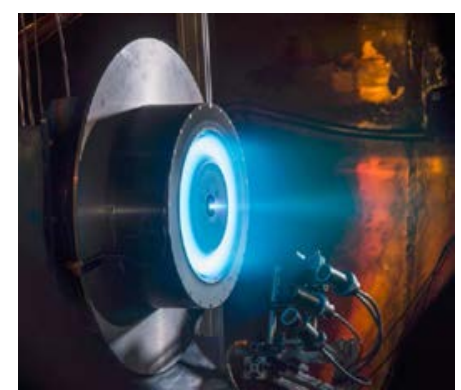

Figure 3. Hall Effect Rocket with Magnetic Shielding (HERMeS). ${ }^{16}$ 
This thruster has demonstrated high-efficiency operation from 6.7 to $12.5 \mathrm{~kW}$ while operating over an $\mathrm{I}_{\mathrm{sp}}$ range from 2000 to $3000 \mathrm{~s}$. Validated models predict robust operation for over $10 \mathrm{t}$ of xenon propellant, enough to provide the 50000 hours needed for ARRM over all expected environmental conditions. ${ }^{16}$

NASA's 300MS thruster demonstrated a magnetic shielding technology retrofit onto an HET capable of operating at $20 \mathrm{~kW},{ }^{18}$ and this technology should be scalable to existing 50-kW HETs. Similarly, the PPU's modular design should be usable to $50 \mathrm{~kW}$, and input voltages could be raised to $300 \mathrm{~V}$ by either using wide-bandgap semiconductors to replace silicon diodes and transistors, or by switching to a series-stacked topology.

\section{Concept Study Methodology}

The COMPASS team at the NASA Glenn Research Center used a data collaboration tool known as the global integrated design environment (GLIDE) to conduct the studies described in this paper. Operating in a concurrent mode, the COMPASS team includes system and subsystem experts for system integration, launch vehicle performance and integration, ground systems, mission operations, flight dynamics, guidance, navigation, control, mechanical systems, propulsion, power, thermal systems, space environments, command and data handling, communications, risk and reliability, computer-aided design, and cost estimation (Fig. 4). The team is co-located in a single room to conduct brainstorming and design sessions, and members conduct individual detailed analyses and literature reviews between sessions. A key to the design process is the real-time participation of the customer or primary investigator. This enables rapid decision making when "forks in the road" appear and ensures that the most valuable solution is found when conflicting requirements appear.

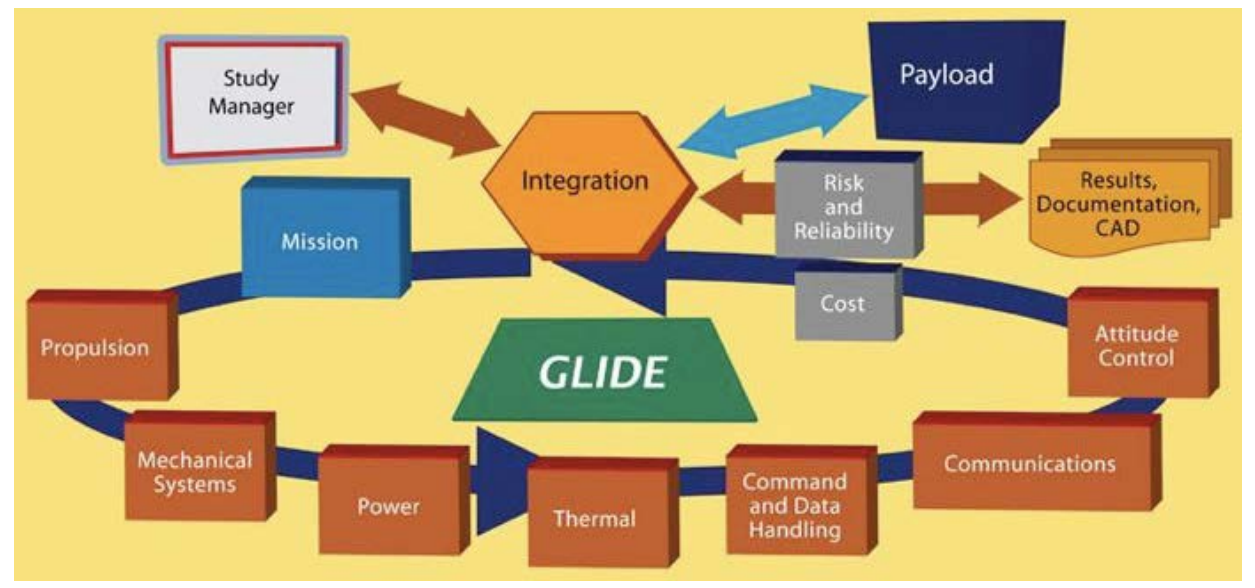

Figure 4. COMPASS process.

Each study begins with a problem definition, including determining the figures of merit, and a literature review of past missions to serve as a starting point. Small groups brainstorm a strawman spacecraft model, and launch vehicle and trajectory options are either determined or specified. The full COMPASS team then works in one location to develop a baseline design using GLIDE, with each vehicle subsystem lead developing his or her own system models with the appropriate level of fidelity. The team iterates the design based on cost, reliability, and risk analyses until all mission-relevant constraints are met. Then variations are developed, if applicable. The team concludes by summarizing the mission and costs, and recording the spacecraft mass and power equipment lists. Any challenges and lessons learned are noted, and opportunities for further study are identified. The entire process typically takes 2 weeks.

Each of the spacecraft described in this paper was designed to have single-fault-tolerant subsystems, where possible. Exceptions to this include the electric power system, propellant tanks, and radiators, which have zero fault tolerance, although they are designed to accommodate some performance degradation. Contingency operations are not included in these analyses; therefore, all design concepts must be treated as preliminary.

Mass growth calculations were conducted according to AIAA S-120-2006, "Standard Mass Properties Control for Space Systems." The percent growth factors specified in this standard were applied to each subsystem before additional growth was applied at the system level. This process ensured an overall growth of at least 30 percent on the dry mass of the entire system. Growth in the propellant mass was included in the propellant calculation. A 30-percent growth factor was used on the bottoms-up power requirements for the bus subsystems, with a 5-percent margin for the electric thruster power requirements. 
The Spacecraft N-body Analysis Program (SNAP) was used to conduct any tangential steering spirals from LEO to higher orbits, and the Mission Analysis Low-Thrust Optimization (MALTO) interplanetary low-thrust trajectory optimization tool was used to determine the propellant mass needed to perform any heliocentric mission phase. Both tools were developed by NASA and are available for use. ${ }^{19}$

Vendor-supplied data were used where possible for mass and volume estimates to provide realism. This does not imply endorsement of any particular commercial system.

For each of the concepts described in this paper, we assumed the use of the solar array and thruster systems described in the previous section. For concepts of nominally $50 \mathrm{~kW}$ or less, the components were sized based on test data from the EDUs. For higher power systems, vendor-provided analyses and/or reasonable engineering assumptions were used to scale test data. The COMPASS team was involved in all nine of these concepts. For eight of the concepts, the COMPASS team ran the first iteration for later detailed analysis by dedicated design teams. The ninth, described in Section IV.C, was developed by the evolvable Mars campaign and the COMPASS team ran alternate analyses for what-if scenarios.

\section{Solar Electric Propulsion Vehicle Concepts}

Nine SEP concepts are described, six that are SEP only and three that combine electric and chemical propulsion into a single spacecraft (SEP-Chem). These concepts are grouped into SEP-only and hybrid SEP-Chem concepts and presented in low- to high-power order to demonstrate a potential cadence of missions leading up to a full mission to the surface of Mars. The SEP-only concepts are designed for the following missions: a round-trip cargo-delivery mission to Mars using a Falcon 9 rideshare, a robotic mission to redirect an asteroid, two extensions of the robotic asteroid mission vehicle, a piloted mission to a NEA, and a cargo mission to Mars per the DRA 5.0 concept architecture. The hybrid SEP-Chem concepts are designed for the following missions: a one-way cargo delivery mission to Mars using a Falcon 9 rideshare, the delivery of two astronauts and medium-sized payloads to Mars, and the delivery of six astronauts and large payloads to Mars per DRA 5.0. The electric propulsion (EP) power required for these missions ranges from $25 \mathrm{~kW}$ for the rideshare concepts to $800 \mathrm{~kW}$ to fulfill DRA 5.0. Power levels shown are end-of-life (EOL) values to the propulsion system unless otherwise noted. The higher power concepts could guide technology development and assist with mission planning, whereas the lower power concepts identify missions that could be done now to demonstrate the capabilities needed for future human missions to Mars.

Nominal configurations and mission operations are described in the remainder of this paper, followed by Table 2, which summarizes all the concepts. Note that all references to specific hardware configurations are notional, and do not represent a preselection of hardware or an endorsement of any vendor.

\section{A. Round-Trip Robotic Solar Electric Propulsion to Mars (25 kW)}

Figure 5 shows a structure configured as a representative (not proprietary) commercial bus. This bus is outfitted with the ROSA flexible blanket solar arrays and magnetically shielded HETs described in Section II.B. Figure 6 shows a stowed view. Two $12.5-\mathrm{kW}$ thrusters operating at an $\mathrm{I}_{\mathrm{sp}}$ of $3000 \mathrm{~s}$ are powered by two 17.5-kW solar arrays, and $1484 \mathrm{~kg}$ of xenon stored in six tanks provide $16,458 \mathrm{~m} / \mathrm{s}$ of $\Delta \mathrm{V}$ for a 148-day stay at Mars. The total mass with growth is $2621 \mathrm{~kg}$, which fits into one-half of a Falcon 9 launch vehicle with insertion into a geostationary transfer orbit (GTO) and includes $46 \mathrm{~kg}$ of payload delivered to Mars. As shown in Fig. 7, ROSA solar arrays with a centerline hinge are used keep the height of the spacecraft down to $4.13 \mathrm{~m}$, allowing an additional $7.3 \mathrm{~m}$ of headroom for a rideshare mission. (Note that this hinged variation was not developed or tested in the work described in Section II.B.) A 1-m-diameter antenna is used for communications to and from Mars via the Deep Space Network. The HETs are mounted on two-axis gimbals, and the reaction control system (RCS) uses a hydrazine monopropellant.

A lunar gravity assist is used for both Earth departure and arrival, with a maximum characteristic energy (C3) of $2 \mathrm{~km}^{2} / \mathrm{s}^{2}$. The electric propulsion (EP) system is used to spiral into and out of a 24-hr circular Mars orbit close to Deimos (semi-major axis $=20082 \mathrm{~km}$ ). The total trip time is 1857 days for a 2018 launch date. This concept could be made more capable with the addition of a chemical thruster for use in the gravity wells around Mars and Earth; see Section V.A for a description of that concept.

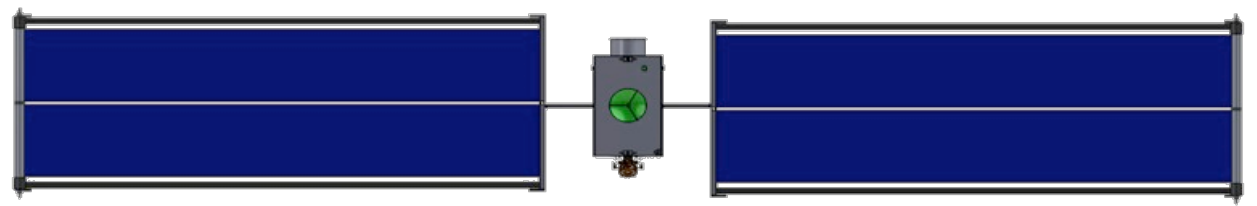

Figure 5. Concept for 25-kW solar electric propulsion for robotic Mars mission. 


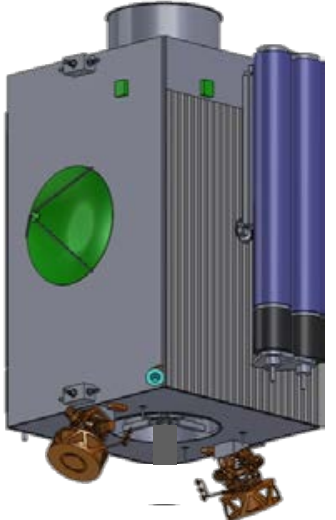

Figure 6. Concept for 25-kW solar electric propulsion.

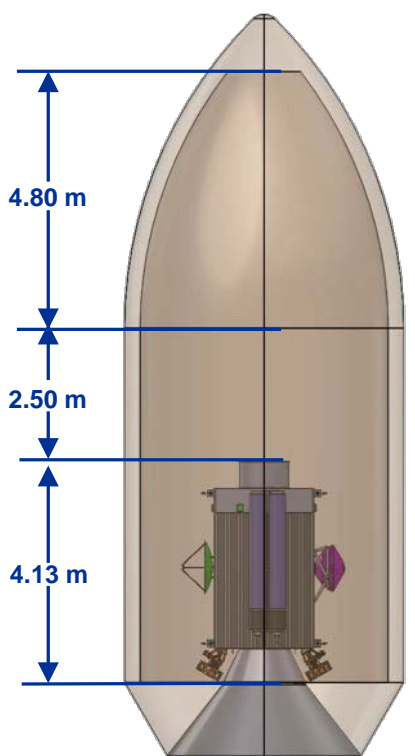

Figure 7. Concept for 25-kW solar electric propulsion for robotic Mars mission shown in a Falcon 9 launch fairing.

\section{B. Robotic Solar Electric Propulsion to a Near-Earth Asteroid $(40 \mathrm{~kW})^{20,21}$}

SEP could be used to redirect a large amount of asteroidal mass to a lunar orbit where crew could collect and analyze samples without requiring long-duration human transport. This mission satisfies a national call to send humans to an asteroid, demonstrates planetary defense techniques, and provides in situ science opportunities that would otherwise be very difficult. Either an entire asteroid could be captured provided that it is on a trajectory already headed close to Earth and is sufficiently small ( $\sim \mathrm{m}$ max. dimension), or a somewhat smaller boulder could be extracted from a larger, more distant asteroid. A 40-kW SEP system could be used to accomplish either objective.

Figure 8 shows the first configuration proposed for this mission. Four magnetically shielded HETs operating at $10 \mathrm{~kW}$ are powered by two 30-kW flexible blanket solar arrays, with $800 \mathrm{~V}$ input to the thrusters to achieve an $\mathrm{I}_{\text {sp }}$ of 3000 s. A fifth thruster string is included as a spare. These parameters are based on the use of the technology

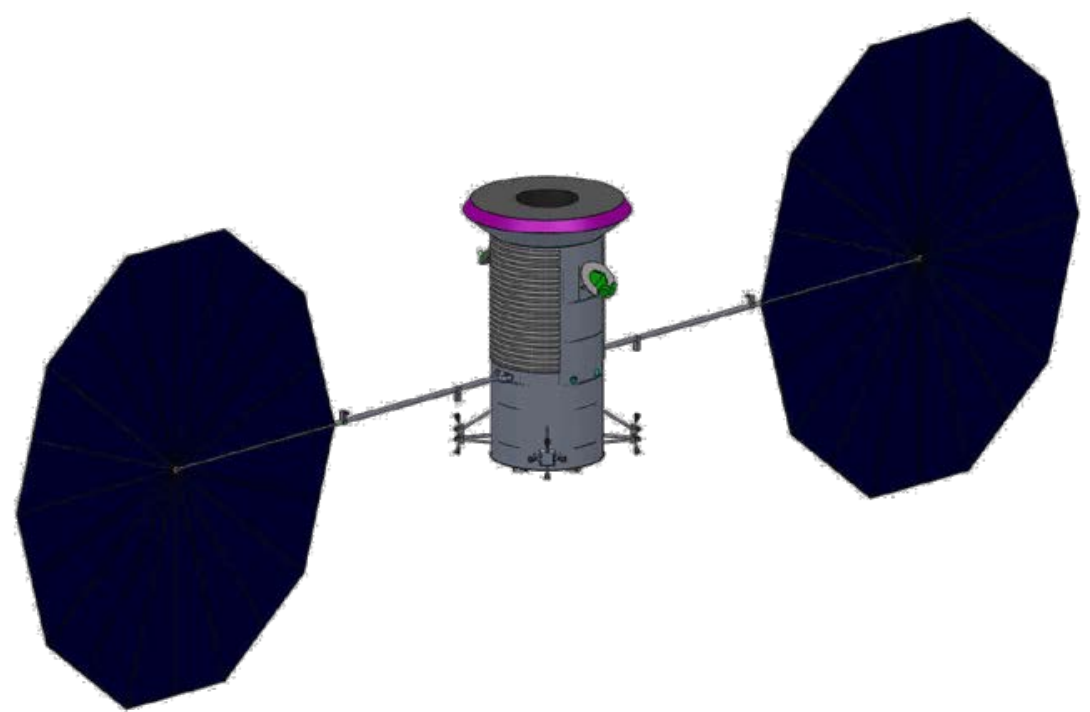

Figure 8. Concept for 40-kW solar electric propulsion for asteroid retrieval mission. 
described in Section II.B. Figure 9 shows the spacecraft stowed in an Atlas V 551-class launch vehicle. To capture the entire asteroid, the solar arrays are mounted on booms that can be folded away from the asteroid during capture to facilitate matching the asteroid's spin state. The 16-t spacecraft is delivered to a 407-km LEO circular orbit. It then spirals for 2.2 years to the Moon for a lunar gravity assist, arriving at the asteroid 1.7 years later. The asteroid is captured within 90 days and is delivered to a lunar orbit within 2 to 6 years, depending on the asteroid's initial trajectory. This results in a $\Delta \mathrm{V}$ of $9.4 \mathrm{~km} / \mathrm{s}$ to capture asteroid $2008 \mathrm{HU} 4$ with an assumed mass of $1000 \mathrm{t}$ using low-thrust SEP. Note that the total flight time could be reduced by over 2 years if a Falcon heavy-class launch vehicle was used to deliver the 11-t spacecraft to LEO: the spacecraft mass would be reduced by the quantity of xenon propellant needed for the spiral out from Earth. This approach was explored to study the capture of a 60-t boulder from asteroid 1998 KY26. The use of SEP enables this mission to be accomplished with a single launch. Options studied using chemical propulsion alone resulted in 12 to 20 times higher initial mass in LEO: $225 \mathrm{t}$ using zero-boil-off $\mathrm{LO}_{2} / \mathrm{LH}_{2}$ and $361 \mathrm{t}$ for space-storable bipropellants. Both chemical-alone options would require multiple launches and in-space assembly. ${ }^{20,22}$

A considerable amount of study has been expended on this concept since the first 2-week study in 2012. The concept has been modified in two primary ways: (1) the SEP stage needed for ARRM could be built using a structure that can accommodate more xenon propellant than is needed to retrieve the asteroidal mass, thereby demonstrating a bus that could be re-used for a much higher power system, and (2) this stage also could use much less xenon propellant $(\leq 5 \mathrm{t})$ to retrieve a smaller asteroidal mass from a body nearer to Earth using structures that would be more amenable to commercial use, ensuring NASA's ability to buy subsequent units and reducing the cost of the mission. This lower capability option could be extended to meet future higher capability needs via a modular retrofit with additional solar arrays, thruster systems, and xenon as described in Section IV.D. Figure 10 shows a concept illustrating the former approach; this is known as the ARRM Block 1 SEP module. For Block 1, $8 \mathrm{t}$ of xenon propellant in four tanks is packaged with four $12.5-\mathrm{kW}$ HETs and two 25-kW flexible blanket solar arrays in a structure that is sized to accommodate $16 \mathrm{t}$ of xenon and $150 \mathrm{~kW}$ of thruster power. ${ }^{21}$ Use of this structure to accommodate the higher capability is described in Section IV.C.

\section{Solar Electric Propulsion Cargo to Mars $(150 \mathrm{~kW})^{23}$}

As previously described, NASA's evolvable Mars campaign includes investigating a split architecture that employs SEP to preposition cargo to Mars and chemical propulsion to transport crew. The Block 1 SEP bus and thruster system concept shown in Fig. 10 was augmented by the evolvable Mars campaign team to provide $150 \mathrm{~kW}$ of electric thruster power by increasing the number of thrusters, the size of the solar arrays, and the number of xenon propellant tanks. The augmentation minimized mission-unique system developments and maximized the reuse of flight-qualified components, Figure 11 shows this structure, which uses eight tanks to store $16 \mathrm{t}$ of xenon propellant; twelve strings of $12.5-\mathrm{kW}, 3000$-s thrusters; and two $85-\mathrm{kW}$ flexibleblanket solar arrays. Four 48-kW ROSA solar array winglets are shown in Fig. 12, two per side in a side-by-side configuration. The dry mass of the SEP stage is $7.68 \mathrm{t}$, and with $16 \mathrm{t}$ of propellant it could deliver a 31-t payload to Mars orbit in 4.6 years using a Space Launch System (SLS) delivery to LEO followed by a spiral trajectory with lunar gravity assist

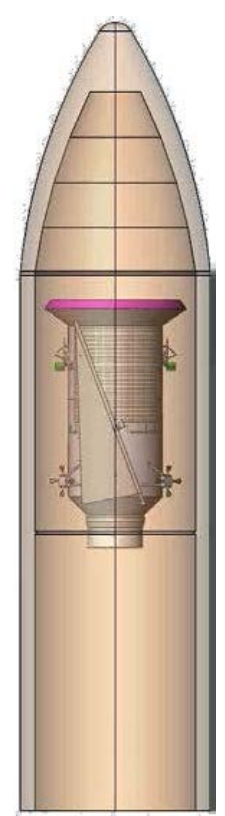

Figure 9. Concept for $\mathbf{4 0 - k W}$ solar electric propulsion stowed on an Atlas V 551-class launch vehicle.

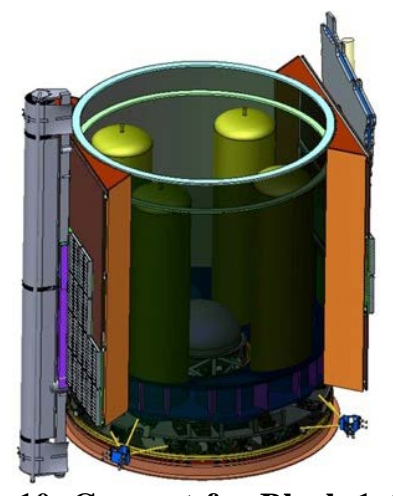

Figure 10. Concept for Block $140-\mathrm{kW}$ solar electric propulsion configured for direct extensibility to $150 \mathrm{~kW} .^{21}$

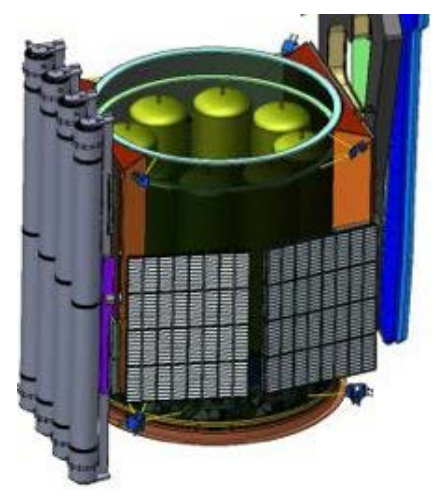

Figure 11. Concept for Block 1a 150-kW solar electric propulsion for Mars cargo missions. ${ }^{21}$ 
for Earth escape. In this case, a heliocentric spiral to Mars is followed by a final spiral to a 1-sol Mars orbit. Alternatively, 29 t could be delivered to orbit around Phobos or Deimos using an additional 73 days for capture, or $41 \mathrm{t}$ could be delivered to a 500-km circular Mars orbit if aerocapture is used. Because the final spiral is not required for this latter case, the total trip time is reduced to 2.8 years and only $11.7 \mathrm{t}$ of xenon are required. ${ }^{23}$ Note that this concept was developed by a subset of the COMPASS team based on a scaling relationship from the Block 1 concept previously described, and did not include a detailed design analysis.

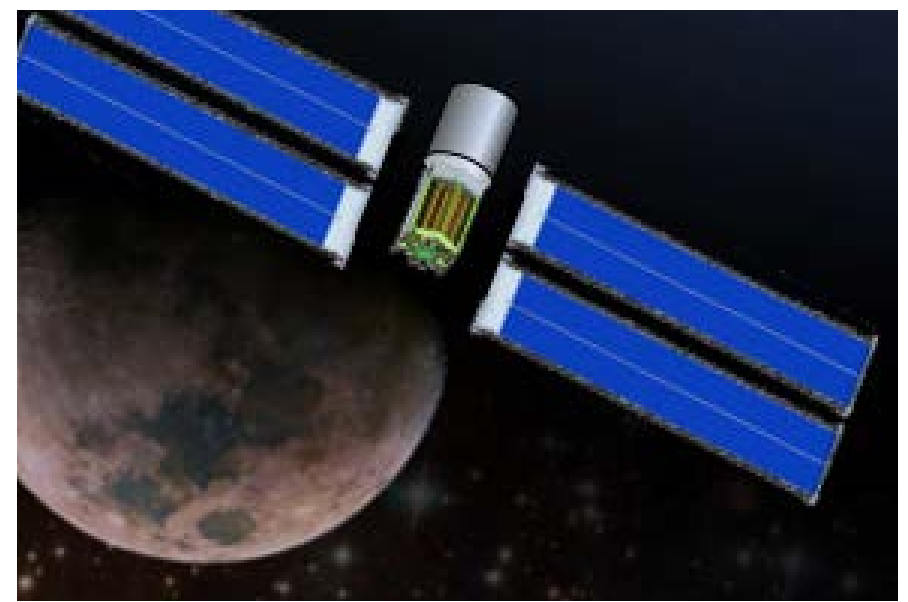

Figure 12. Concept for Block 1a 150-kW solar electric propulsion system for transporting cargo to Mars orbit. ${ }^{21}$

\section{Solar Electric Propulsion Cargo to Mars $(150 \mathrm{~kW})^{24}$}

The previous section describes a concept that can scale a 10-t "Block 1" SEP stage up to a 16-t "Block 1a" SEP stage. An alternative building-block approach to transitioning from an ARRM mission to a Mars mission is to use a smaller SEP module with nominally $5 \mathrm{t}$ of xenon to accomplish the ARRM mission (with a smaller asteroidal mass return) and then retrofit it with a module that provides the additional power, propellant, and thrust needed for a Mars mission.

Figure 13 shows the high-delta-V retrofit (HDR) unit with two 75-kW MegaFlex solar arrays, $18 \mathrm{~m}$ in diameter, on 10-m booms extending from a 2.94-m-diameter cylindrical structure. The $10-\mathrm{m}$ boom length was chosen to provide clearance for the two 25-kW solar arrays on the 5-t SEP stage shown mounted below the HDR. The solar arrays are gimbaled at the array side of the booms. A crew habitat is shown mounted to a docking module above the HDR. The cylindrical HDR structure houses $11 \mathrm{t}$ of xenon propellant in eight Composite Overwrapped Pressure Vessel (COPV) tanks and eight 13.5-kW PPUs. Eight 12.5-kW magnetically shielded HETs are mounted on four booms that extend down the outer corners of the 5-t SEP module; $90^{\circ}$ hinged platforms orient the thrusters in the same plane as the four thrusters in the 5-t SEP module; and power from the PPUs and propellant feedlines is fed through the booms to the thrusters.

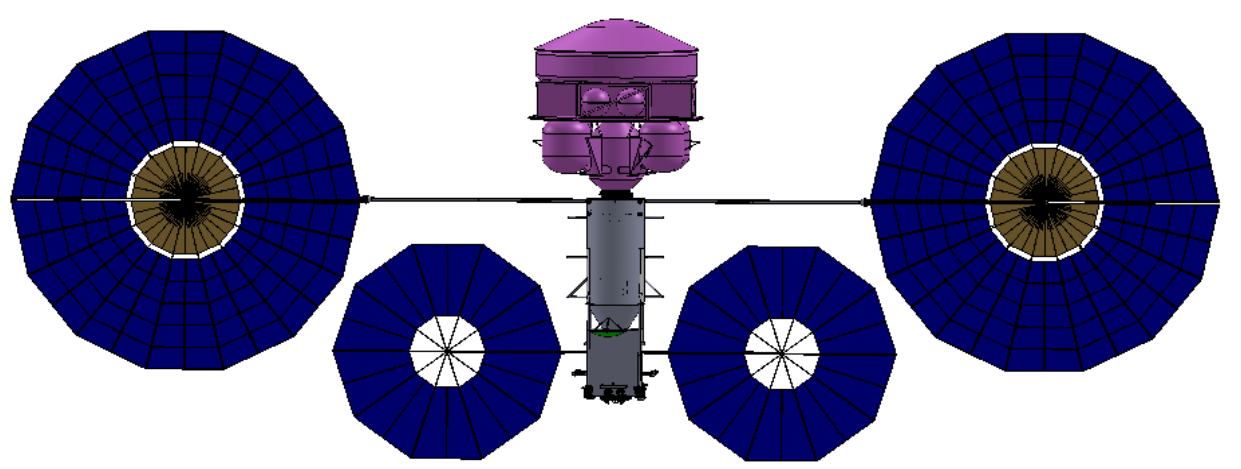

Figure 13. Concept for high-delta-V retrofit, showing Asteroid Retrieval Robotic Mission solar electric propulsion stage (bottom) and lander (top). 
Figure 14 shows the HDR and the 5-t SEP module stowed for launch, with the HDR supporting the lower-mass SEP module and both the HDR and SEP module mounted above an 18-t lander via a strongback. The image shows an SLS 2B ASB fairing with a 10-m-diameter shroud. The combined dry mass of the HDR and SEP stage is $7.7 \mathrm{t}$, together producing $190 \mathrm{~kW}$ at beginning of life (BOL) and holding $16 \mathrm{t}$ of xenon. If it is assumed that the SLS delivers the system to a $200-$ by $20586-\mathrm{km} 28.5^{\circ}$ orbit, the spiral from Earth would take 575 days, followed by a 601-day spiral to Mars. The spacecraft would deliver a 45-t payload to Mars orbit in 3.4 years if it is assumed that the thrusters operate at an $\mathrm{I}_{\mathrm{sp}}$ of $3000 \mathrm{~s}$. The 45-t lander is assumed to deliver $19 \mathrm{t}$ of payload to the surface via an inflatable aeroshell.

For piloted missions, the HDR and smaller SEP module would be launched to a lunar high rectilinear orbit by an SLS 1B launch vehicle for rendezvous with a habitat module. Before rendezvous, the HDR/SEP system would use the guidance, navigation, and control (GN\&C) on the small SEP module. After rendezvous, that function would be idled and the habitat GN\&C would take over for the remainder of the mission.

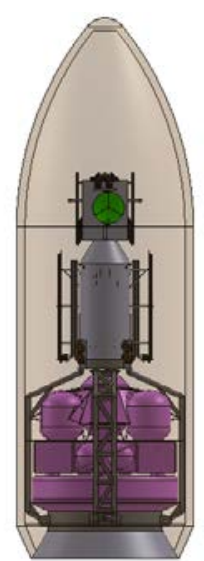

Figure 14. High-delta-V retrofit (middle), solar electric propulsion module (top), and lander (bottom) stowed for launch.

\section{E. Solar Electric Propulsion Crew to a Near-Earth Asteroid $(300 \mathrm{~kW})^{25}$}

In addition to investigating the ability of an SEP to bring an asteroid to cislunar space to enable crew exploration with short-duration human transport (as described in Sec. IV.B), NASA studied the use of SEP to transport crew directly to a NEA per NASA's Human Exploration Framework Team (HEFT) Design Reference Mission 34B. This mission assumed that two SEP stages would be launched into a 407-km circular Earth orbit by a heavy-lift launch vehicle with a 100-t payload capacity and an 8.5- by 25-m shroud. One launch would boost a chemical propulsion stage to the Earth-Moon Lagrange point 1 (E-M L1). The other launch would send off a 24.4-t habitat, a 6.7-t exploration vehicle, and an 8.2-t kick stage; the kick stage would boost the SEP stage and the other two elements to E-M L1 for rendezvous with the prepositioned chemical stage and a crew vehicle launched directly to E-M L1. The SEP stage would transport the crew to asteroid 2008 EV-5 for a 30-day exploration mission and then return the crew vehicle to Earth orbit. ${ }^{10,13}$

We developed an SEP concept using this mission as a target so that we could run parameterized studies to guide technology development for the key SEP components and subsystems. Figure 15 shows two Mega-ROSA solar arrays producing $381 \mathrm{~kW}$ of power at BOL at $1 \mathrm{AU}$ to provide $300 \mathrm{~kW}$ of power to the thrusters at EOL and at asteroid $2008 \mathrm{EV}-5$, and $20 \mathrm{~kW}$ of power for the habitat and housekeeping.

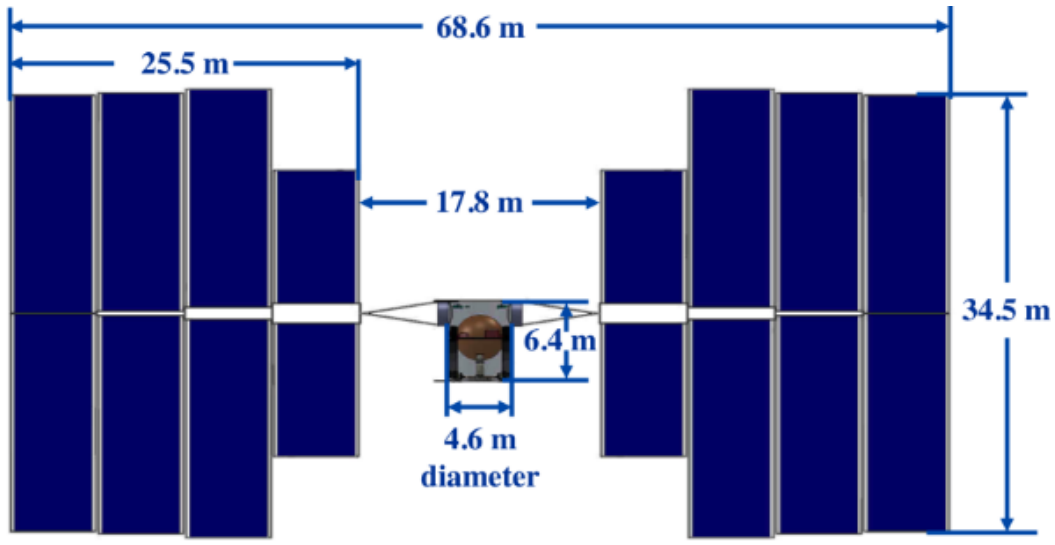

Figure 15. Concept for 300-kW solar electric propulsion for piloted near-Earth asteroid mission. 
Figure 16 shows an interior view of the bus with the solar arrays stowed. At this high power level, we found that increasing the bus voltage higher than $120 \mathrm{~V}_{\mathrm{DC}}$ would provide a significant mass savings. Specifically, increasing the bus voltage to $300 \mathrm{~V}$ would save $1250 \mathrm{~kg}$ in dry mass because less copper would be needed for the wiring harness, which would carry less current, and would permit direct-drive thruster operation, which would increase the mass savings to $2.2 \mathrm{t}$. Because every 1 $\mathrm{kg}$ decrease in dry mass results in 1-kg less propellant, the total reduction in launch mass was $4.4 \mathrm{t}$. When we compared the use of ten 30-kW HETs with the use of seven 50-kW HETs, we found that the larger thrusters increased system mass rather than reducing it. This is because a spare 50$\mathrm{kW}$ thruster was carried, whereas the risk of losing one thruster was considered to be acceptable when a larger number of smaller units was used. We assumed that the thrusters were operating with a fixed $\mathrm{I}_{\mathrm{sp}}$ of 2000 $\mathrm{s}$ via the direct drive at $300 \mathrm{~V}$. The vehicle wet mass with growth was 46.4 $\mathrm{t}$, including $36 \mathrm{t}$ of xenon propellant, and the total $\Delta \mathrm{V}$ was $10 \mathrm{~km} / \mathrm{s}$. The total trip time for this concept was 723 days, which included 340 days to spiral out of Earth's orbit. ${ }^{25}$

Other considerations for the development of this class of SEP vehicle are described by Capadona et al. ${ }^{26}$

\section{F. Solar Electric Propulsion Cargo to Mars (440 kW)}

A concept to achieve NASA's DRA 5.0 using a split architecture is shown in Fig. 17. Two ROSA solar arrays are shown, each providing 500 $\mathrm{kW}$ at beginning of life to provide $440 \mathrm{~kW}$ to sixteen HETs operating at $50 \mathrm{~kW}$ and $3000 \mathrm{~s} \mathrm{I}$ sp. The solar arrays also provide $10 \mathrm{~kW}$ of power to the habitat and $10 \mathrm{~kW}$ to housekeeping loads. A 120-t-capable heavy launch vehicle with a 10- by $17-\mathrm{m}$ fairing delivers the SEP spacecraft to a 407-km circular orbit, where it docks with a 100-t cargo element and spirals to Earth escape. The spiral lasts 972 days and is followed by a 230-day Mars transit. Aerocapture is used to deliver the payload to the surface.

\section{Hybrid Solar Electric Propulsion-Chemical Vehicle Concepts}

The following concepts combine electric and chemical propulsion systems into a single vehicle (SEP-Chem). The electric thrusters are used over long interplanetary distances, whereas the chemical rockets are used to eliminate the need for long spiral trajectories into and out of the gravity wells at Mars and Earth.

\section{A. Hybrid Solar-Electric/Chemical Propulsion Robotic Mission to Mars (25 kW)}

A chemical rocket was added to the 30-kW concept described in Section IV.A to form a relatively low power hybrid SEP-Chem system that could be launched within one-half of a Falcon 9 fairing to reduce costs via ridesharing. The launch configuration is the same as that shown in Fig. 6. A standard orbit-raising sequence from injection into GTO is followed by an electric propulsion spiral to lunar gravity assist (C3 $=-2 \mathrm{~km}^{2} / \mathrm{s}^{2}$ ) and a 300-day EP transit to arrive at a slightly hyperbolic Mars orbit. This EP portion of the trip requires $4125 \mathrm{~m} / \mathrm{s}$ of $\Delta \mathrm{V}$. Capture into a high elliptic Mars orbit (300-km perigee altitude inclined at $14^{\circ}$ ) is accomplished with a $269-\mathrm{m} / \mathrm{s}$ chemical burn from which a payload could be deployed. Up to $65 \mathrm{~kg}$ of payload could be carried, permitting the deployment of simple weather or seismometer landers that could use the SEP-Chem spacecraft as a communications relay or weather satellite. Reconnaissance flybys of Phobos and Deimos, or payload delivery to these moons, are also possible. If rideshare is not required, then additional xenon and chemical fuel could be added to allow for a sample return system and a return-to-Earth. Alternatively, larger Mars payloads could be carried, such as a subscale Mars lander with an in situ resource utilization demonstration unit, or a fleet of small science rovers. Reconnaissance flybys of Phobos and Deimos, or payload delivery to these moons, is also possible.

Chemical fuel, oxidizer, and pressurant tanks for $221 \mathrm{~kg}$ of bipropellant are mounted within the previously unused center tube of the structure, with a single 100-lbf Advanced Material Bipropellant Rocket (AMBR) thruster added below, as shown in Fig. 18. The amount of xenon propellant is reduced to $618 \mathrm{~kg}$, of which $584 \mathrm{~kg}$ is usable.

11

American Institute of Aeronautics and Astronautics 
The same pair of 17-kW solar arrays and 12.5-kW HETs described in Section IV.A are used to provide $35 \mathrm{~kW}$ of BOL power and $30 \mathrm{~kW}$ to the EP system. The hinged ROSA arrays are shown stowed in Fig. 19.

The use of rideshare and already demonstrated SEP components provide a very capable system for relatively low cost. A round-trip variation of this concept also was studied. We found that $1059 \mathrm{~kg}$ of xenon and $462 \mathrm{~kg}$ of bipropellant could provide a 400-day stay at Mars with a total mission time of 1100 days, if a launch date of 2020 is assumed. In this case, the SEP spacecraft would require only two-thirds of the Falcon 9. This system might be able to return Mars samples to Earth if it was used with a Mars ascent vehicle large enough to place the sample in a high elliptic parking orbit.

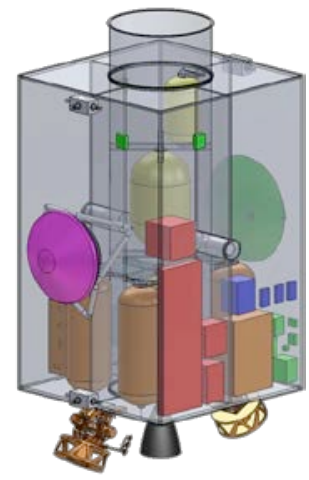

Figure 18. Concept for 25-kW hybrid solarelectric/chemical propulsion spacecraft for Mars mission (interior view).

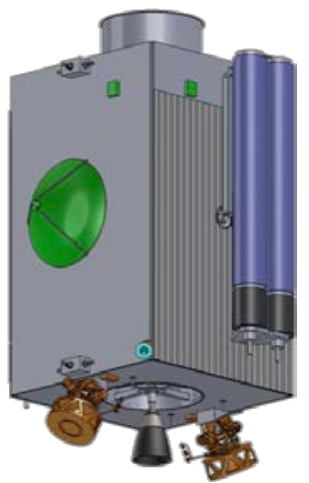

Figure 19. Concept for 25-kW hybrid solarelectric/chemical propulsion spacecraft for Mars mission (exterior view).

\section{B. Hybrid Solar-Electric/Chemical Propulsion Piloted Mission to Mars $(320 \text { kW) })^{27}$}

In Section IV.C, a Block 1a SEP concept is described that extends the performance of the 40-kW Block 1 SEP stage described in Section IV.B while minimizing the number of systems that would need to be newly space qualified. Taking that approach one step further, a Block 2 SEP system concept was developed that uses the Block 1a structures and subsystems to provide $320 \mathrm{~kW}$ of power to the electric thrusters and integrates chemical thrusters to provide sufficient capability to transport four astronauts during a conjunction-class mission to the Mars surface. An SLS 2B launch vehicle delivers the nearly empty hybrid SEP-Chem stage with a habitat module to a lunar flyby orbit. The electric thrusters are used first to spiral out to a lunar distant retrograde orbit (LDRO) using a lunar gravity assist, and to then spiral out to a lunar distance high Earth orbit (LDHEO) for rendezvous with a resupply

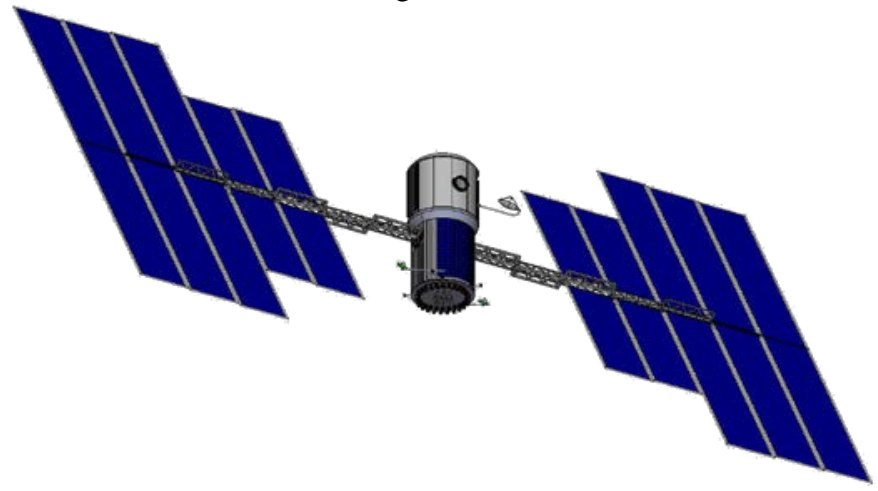

Figure 20. Concept for 320-kW hybrid solar-electric/chemical propulsion (exterior view).

tanker. The tanker supplies the majority of the xenon and hypergolic $\mathrm{MMH} / \mathrm{N}_{2} \mathrm{O}_{4}$ propellant needed for the mission. Additional flights are needed to outfit the consumables on the habitat. Once refueled and outfitted, the SEP-ChemHabitat vehicle rendezvous with a four-astronaut Orion capsule. The crew transfers out of Orion into the habitat, after which the Orion capsule is jettisoned. The low-thrust EP is used nearly continuously until it reaches a 150-km Mars orbit periapsis, where chemical propulsion is used to insert into a 5- to 10-sol high elliptical orbit. This high orbit was chosen to reduce propellant load. A Mars taxi that has been predeployed using a separate hybrid SEPChem system could then be used to transport the crew to Phobos. 
Although this option requires tankers and habitat-consumable launches, it allows for the reuse of the SEP-Chem stage and habitat for a follow-on Mars mission, significantly reducing the capital expenditure needed for the second mission.

Key features of this hybrid system include the use of the technologies described in Section II.B, configured as shown in Figs. 20 and 21. The two $200-\mathrm{kW}$ Mega-ROSA solar array wings are each composed of six 25-kW and four $12.5-\mathrm{kW}$ winglets that provide $300 \mathrm{~V}$ of regulated power to 24 PPUs. Each PPU drives the HET described in Section II.B, operated at $13.3 \mathrm{~kW}$. The larger winglets are sized to be reused for the Block 1 concept, and the smaller winglets are sized to minimize thruster plume impingement on the PV elements. A $300-\mathrm{V}$ bus voltage is used to reduce the mass of the wiring harness. The total wet mass with growth is $47.9 \mathrm{t}$; this includes $1.6 \mathrm{t}$ of xenon propellant, the balance of the $16 \mathrm{t}$ of xenon and $16 \mathrm{t}$ of hypergolic propellant is delivered by a tanker by a separate launch. The hybrid spacecraft stows into a 7.5-m-diameter dynamic envelope and an 8.4-m payload fairing with a 12-m extension, as shown in Fig. 22.

Other variations of this concept that were analyzed include using the SEP Block 1a structure in a side-by-side configuration with chemical propulsion added to each side, and SEP-only configurations to transport cargo in conjunction with chemically propelled spacecraft to transport crew. ${ }^{27,28}$

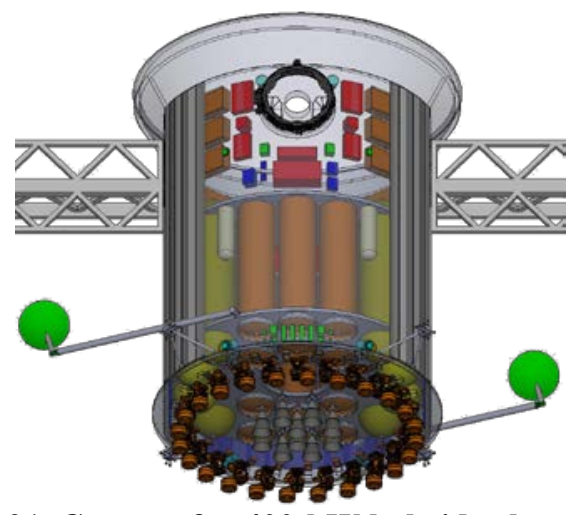

Figure 21. Concept for 400-kW hybrid solar-electric/ chemical propulsion (interior view).

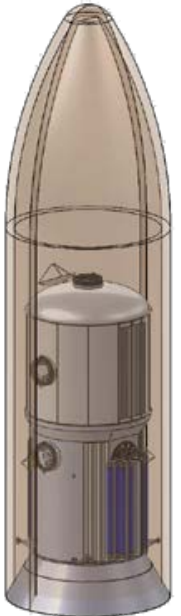

Figure 22. Concept for Block 2 400-kW hybrid SEP-Chem stowed in a Space Launch System with a deep space habitat.

\section{Hybrid Solar-Electric/Chemical Propulsion Piloted Mission to Mars $(800 \mathrm{~kW})^{29}$}

NASA published DRA 5.0 in 2009 to describe a highly capable long-duration human exploration of the Mars surface. This architecture assumes that the in-space transportation system is required to transport six astronauts and all associated life support, power, and mobility systems for an outpost that could support 700-day excursions. With a hybrid SEP-Chem system, the crew can be transported with only two launches to low Earth orbit, one to insert the SEP-Chem stage and the other to deliver the fully outfitted habitat. When this study was done in 2012, we assumed an SLS launch vehicle that could only launch to a suborbital location; therefore, the optimal split required the habitat to be launched with part of the xenon propellant as well as a chemical insertion stage. The hybrid SEP-Chem concept supplies $800 \mathrm{~kW}$ to eight 125-kW nested HETs operated at $2400 \mathrm{~s}$ using 1000-kW BOL Mega-ROSA solar arrays configured as shown in Fig. 23. Twenty 50-kW HETs would provide identical performance regarding trip time and system mass, but the nested thrusters would be easier to package. Their configuration is shown in Fig. 24: two banks of four thrusters are mounted on side flanges at the bottom face of the spacecraft. Two Orion-derived storable chemical systems are mounted in between the electric thrusters. Two chemical fuel and two oxidizer tanks are shown in yellow directly above the chemical nozzles, with two pressurant tanks filling gaps between the tanks and the exterior structural wall. Two 3.9-m-diameter spherical COPV tanks shown in orange store $109 \mathrm{t}$ of xenon, and two $2.5-\mathrm{kW}$ commissioning solar arrays provide power until the large arrays deploy. Deployable radiator panels are shown in gray below the partial view of the solar array backbone structure. Solar array gimbals based on those used on the International Space Station are shown in lavender attached to the structural wall. Ten 8.73- by 27.3-m ROSA winglets provide a total area of $2383 \mathrm{~m}^{2}$ per wing and are connected to the spacecraft by a $12-\mathrm{m}$ yoke. A 
power bus voltage of $500 \mathrm{~V}$ was used to further reduce the mass of the wiring harness. The total trip time using this hybrid spacecraft is 1065 days round trip, which is only 151 days longer than the nuclear thermal concept and 185 days longer than the all-chemical concepts studied for the same mission. The hybrid spacecraft requires five fewer heavy launches than the all-chemical concept. ${ }^{30}$ NASA's DRA 5.0 (Ref. 11) was amended to include this concept as an SEP variation in $2014 .{ }^{31}$

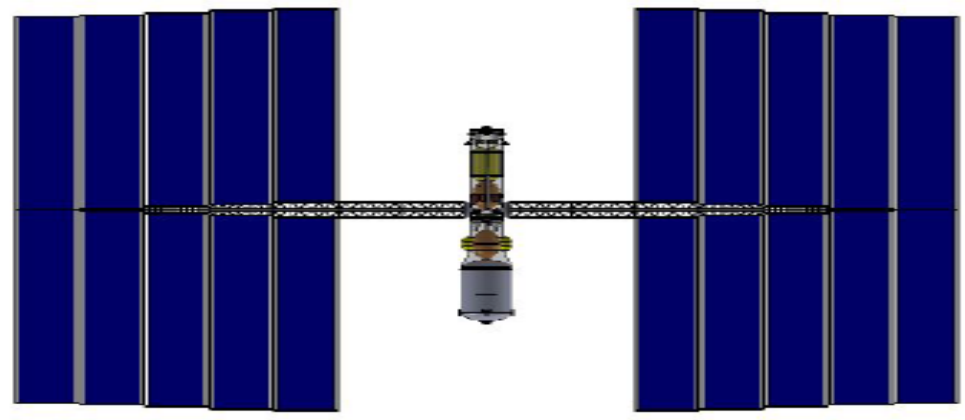

Figure 23. Concept for Hybrid 800-kW solar-electric/chemical propulsion for transporting six astronauts to Mars.

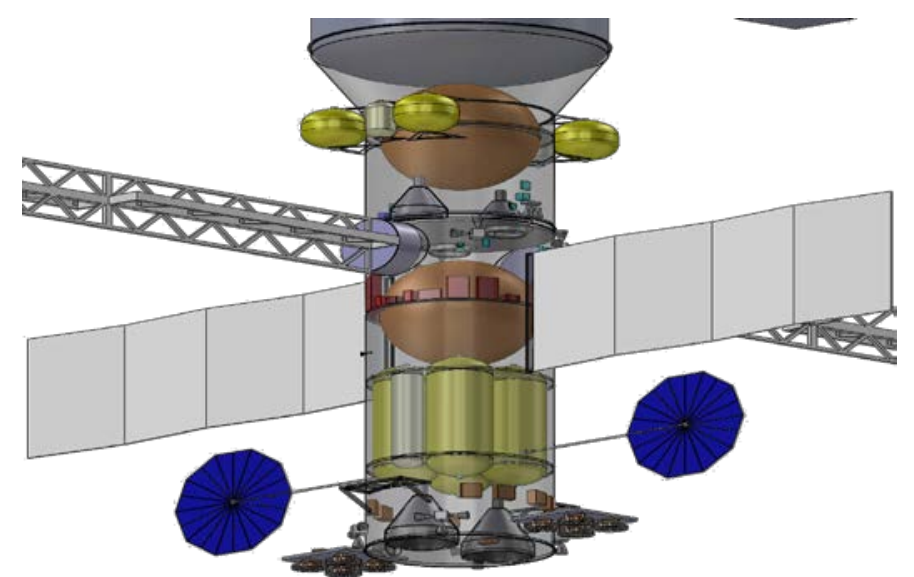

Figure 24. Interior view of hybrid 800-kW SEP-Chem concept.

This spacecraft was designed to transport six astronauts and both a 10-t Orion module and a 54-t deep space habitat to a 1-sol Mars orbit and back without refueling tankers. This mirrored the assumptions made for DRA 5.0, with the mass of the deep space habitat increased to account for additional consumables required by the longer trip time. Note that the SEP-Chem vehicle is twice the size of the vehicle described in Section V.B, which was configured to transport four astronauts with a 19-t deep space habitat without Orion to a 5-sol orbit, and required additional launches for refueling and consumables.

\section{Summary}

Table 2 summarizes each of the concepts described in Sections IV and V. Solar array and thruster technologies are described in Section II.B. Solar power values are given at beginning of life (BOL) at $1 \mathrm{AU}$ and $28{ }^{\circ} \mathrm{C}$ and assume the use of the photovoltaic (PV) cells as noted, where TJ indicates state-of-the-art triple-junction cells and IMM indicates inverted metamorphic multijunction cells. End-of-life (EOL) power is equal to the total power to the thrusters as listed in the Electric Propulsion row, plus typically $15 \mathrm{~kW}$ for housekeeping loads. Power processing is achieved by either a conventional power processing unit (PPU) or a direct drive unit with the assumed input voltage as listed. The number of HETs, input power per thruster, and specific impulse $\left(\mathrm{I}_{\mathrm{sp}}\right)$ also are listed in the Electric Propulsion row. The total amount of xenon propellant and the number of tanks is listed, along with the total amount of bipropellant fuel for the hybrid SEP-Chem concepts. The total delta-V $(\Delta \mathrm{V})$ and trip times are listed for the missions that were described for each concept, as well as the launch configuration and launch mass. Finally, the amount of cargo carried, the number of crew (if applicable), and trip times are listed for each concept. 
Table 2. Summary Solar Electric Propulsion and Hybrid Solar-Electric-Chemical Propulsion Design Features

\begin{tabular}{|c|c|c|c|c|c|c|c|c|c|}
\hline \multirow[b]{2}{*}{ Described in Section: } & \multicolumn{6}{|c|}{ SEP Vehicle } & \multicolumn{3}{|c|}{ Hybrid SEP-Chemical Vehicle } \\
\hline & IV.A & IV.B & IV.C & IV.D & IV.E & IV.F & V.A & V.B & V.C \\
\hline Mission & $\begin{array}{l}\text { Round-trip robotic } \\
\text { Mars } \\
\end{array}$ & Robotic NEA & Cargo to Mars & Cargo to Mars & Crew to NEA & $\begin{array}{l}\text { Cargo to Mars } \\
\text { surface }\end{array}$ & $\begin{array}{c}\text { One-way robotic to } \\
\text { Mars orbit }\end{array}$ & $\begin{array}{c}\text { Crew to Mars } \\
\text { surface }\end{array}$ & $\begin{array}{c}\text { Crew to Mars } \\
\text { surface }\end{array}$ \\
\hline $\begin{array}{l}\text { Solar power (PV\% at } \\
\left.1 \mathrm{AU}, 28^{\circ} \mathrm{C}, \mathrm{BOL}\right)\end{array}$ & $\begin{array}{c}\text { 35-kW } \\
28.8 \% \text { TJ cells }\end{array}$ & $\begin{array}{c}\text { 58-kW } \\
33 \% \text { IMM }\end{array}$ & $190-\mathrm{kW}$ & $\begin{array}{l}\text { 150-kW } \\
33 \% \text { IMM }\end{array}$ & $\begin{array}{c}\text { 381-kW } \\
\text { 33\% IMM cells }\end{array}$ & $\begin{array}{c}500-\mathrm{kW} \\
33 \% \text { IMM cells }\end{array}$ & $\begin{array}{c}35-\mathrm{kW} \\
28.8 \% \mathrm{TJ} \text { cells }\end{array}$ & $\begin{array}{c}435-\mathrm{kW} \\
29.5 \% \text { GaAs } \\
\text { TJ cells }\end{array}$ & $\begin{array}{c}\text { 1000-kW } \\
33 \% \text { IMM }\end{array}$ \\
\hline Power processing & $100-\mathrm{V}$ PPU & $120-V$ PPU & PPU & 100-V PDU & 300-V direct drive & 300-V direct drive & $100-\mathrm{V}$ PPU & PPU & $500-\mathrm{V}$ PDU \\
\hline $\begin{array}{l}\text { Electric propulsion } \\
\text { (total power, power } \\
\text { per thrusters, I } \text { Isp } \text { ) }\end{array}$ & $\begin{array}{c}25 \mathrm{~kW} \text { : two } 12.5-\mathrm{kW} \\
\text { HETs (3000 s) }\end{array}$ & $\begin{array}{c}40 \mathrm{~kW} \text { : four + one } \\
\text { 10-kW HETs/PPUs } \\
\text { (3000 s) }\end{array}$ & $\begin{array}{c}150 \text { kW: twelve 12.5- } \\
\text { kW HETs } \\
\text { (3000 s) }\end{array}$ & $\begin{array}{c}100 \mathrm{~kW} \text { : eight } \\
\text { 12.5-kW HETs (3000 s) }\end{array}$ & $\begin{array}{l}300 \mathrm{~kW} \text { : ten } 30-\mathrm{kW} \\
\text { HETs (2000 s) }\end{array}$ & $\begin{array}{l}440 \mathrm{~kW} \text { : fifteen + } \\
\text { one 50-kW HETs } \\
(3000 \mathrm{~s})\end{array}$ & $\begin{array}{c}25 \mathrm{~kW}: \text { two } \\
\text { 12.5-kW HETs } \\
(3000 \mathrm{~s})\end{array}$ & $\begin{array}{c}320 \mathrm{~kW}: \\
\text { twenty-four } \\
\text { 13.3-kW HETs } \\
(3000 \mathrm{~s})\end{array}$ & $\begin{array}{l}800 \mathrm{~kW}: \text { twenty } \\
\text { 50-kW HETs } \\
(2400 \mathrm{~s})\end{array}$ \\
\hline $\begin{array}{l}\text { Xenon capacity } \\
\text { (total) }\end{array}$ & $1.5 \mathrm{t}$ & $12.9 \mathrm{t}$ & $16 \mathrm{t}$ & $11.4 \mathrm{t}$ & $35.6 \mathrm{t}$ & $50 \mathrm{t}$ & $0.6 \mathrm{t}$ & $22 \mathrm{t}$ & $109 \mathrm{t}$ \\
\hline Xenon tanks & 6 & 7 & 8 & 8 & 1 & 12 & 4 & 12 & 2 \\
\hline Chemical propulsion & & & & & & & 100-lbf AMBR & $\begin{array}{c}\text { Eight + two AR-42 } \\
890 \mathrm{~N}, 300 \mathrm{~s} \mathrm{I}_{\mathrm{sp}} \\
\end{array}$ & Four AJ10 engines \\
\hline Bipropellant capacity & & & & & & & $0.2 \mathrm{t}$ & $17 \mathrm{t}$ & $43.7 \mathrm{t}$ \\
\hline Total $\Delta \mathrm{V}$ & $16.46 \mathrm{~km} / \mathrm{s}$ & $9.57 \mathrm{~km} / \mathrm{s}$ & $10.45 \mathrm{~km} / \mathrm{s}$ & $2.33 \mathrm{~km} / \mathrm{s}$ & $10 \mathrm{~km} / \mathrm{s}$ & $10 \mathrm{~km} / \mathrm{s}$ & $7.41 \mathrm{~km} / \mathrm{s}$ & $\begin{array}{c}\text { SEP: } 6.5 \mathrm{~km} / \mathrm{s} \\
\text { Chem: } 0.675 \mathrm{~m} / \mathrm{s}\end{array}$ & $\begin{array}{l}\text { SEP: } 6.78 \mathrm{~km} / \mathrm{s} \\
\text { Chem: } 0.55 \mathrm{~km} / \mathrm{s}\end{array}$ \\
\hline $\begin{array}{l}\text { Total mass } \\
\text { (with growth) }\end{array}$ & $3116 \mathrm{~kg}$ & $15975 \mathrm{~kg}$ & $7680 \mathrm{~kg}$ & $16090 \mathrm{~kg}$ & $46361 \mathrm{~kg}$ & $87770 \mathrm{~kg}$ & $2621 \mathrm{~kg}$ & $22020 \mathrm{~kg}$ & $237829 \mathrm{~kg}$ \\
\hline Launch fairing & $\begin{array}{l}\text { 4.6-m-diameter } \\
\text { payload fairing }\end{array}$ & Atlas V 551-class & SLS & $\begin{array}{l}\text { 8.4-m SLS with } \\
12-\mathrm{m} \text { extension }\end{array}$ & 8.5- by $25-m$ SLS & 10- by $17-m$ SLS & 1/2 of Falcon 9 & 8.4-m SLS & 8.5- by $25-\mathrm{m} \mathrm{SLS}$ \\
\hline Injection orbit & LEO & LEO & $\begin{array}{l}\text { Elliptical Earth orbit, } \\
\qquad \mathrm{C} 3=-2 \mathrm{~km}^{2} / \mathrm{s}^{2}\end{array}$ & $\begin{array}{c}\mathrm{C} 3=-1.93 \mathrm{~km}^{2} / \mathrm{s}^{2} \\
\text { to lunar manifold } \\
\text { trajectory }\end{array}$ & LEO & LEO & GTO & $\begin{array}{c}\text { LDRO } \\
\text { C3 }=-2 \mathrm{~km}^{2} / \mathrm{s}^{2}\end{array}$ & LEO \\
\hline $\begin{array}{l}\text { Launch } \\
\text { configuration }\end{array}$ & Rideshare on Falcon 9 & Dedicated launch & Dual launch with cargo & $\begin{array}{l}\text { Dual launch with SEP } \\
\text { module and lander }\end{array}$ & $\begin{array}{l}\text { Dual launch with deep } \\
\text { space habitat }\end{array}$ & Dedicated launch & $\begin{array}{l}\text { Rideshare on } \\
\text { Falcon } 9\end{array}$ & $\begin{array}{l}\text { Number of SLS: } 3 \\
\text { for cargo to LDRO } \\
+2 \text { for crew to HEO } \\
\end{array}$ & $\begin{array}{l}\text { Dual launch with } \\
\text { deep space habitat } \\
\text { and Orion }\end{array}$ \\
\hline $\begin{array}{l}\text { Cargo capability } \\
\text { (or size of crew) }\end{array}$ & $35 \mathrm{~kg}$ & N/A & $31 \mathrm{t}$ & $45 \mathrm{t}$ & (4 crew) & $100 \mathrm{t}$ & $50 \mathrm{~kg}$ & (4 crew) & (6 crew) \\
\hline $\begin{array}{l}\text { Destination duration } \\
\text { (stay time) }\end{array}$ & 148 days & 90 days & 400 days & 30 days & 30 days & 300 days & 400 days & 300 days & 300 days \\
\hline Total flight time & 1,857 days & 3,723 days & 1,679 days & 478 days & 723 days & 1,950 days & 1,788 days & 769 days & 1,065 days \\
\hline
\end{tabular}




\section{Conclusion}

We have developed several high-power solar electric propulsion (SEP) concepts to show how newly developed electric thrusters and solar arrays could be used for the cost-effective human exploration of the inner solar system. These concepts provide guidance for the development of these new technologies by identifying the performance parameters most important for system-level improvements and help to bring awareness of SEP capabilities for human exploration. Pure SEP concepts with electric thruster power levels ranging from 25 to $440 \mathrm{~kW}$ could be used for missions to Mars and near-Earth asteroids (NEAs), and chemical propulsion systems integrated with SEP could substantially reduce trip times in comparison to pure SEP systems while substantially reducing launch mass in comparison to pure chemical systems, as demonstrated by the 25- to $800-\mathrm{kW}$ hybrid systems described in this paper.

This steady sequence of capability provides the opportunity to do interesting missions along the way and can lead to a full DRA 5.0 Mars capability requiring fewer heavy lift launches than all-chemical or nuclear thermal propulsion architectures. On the low-power end of the spectrum, commercial and military applications also exist. Developing experience with these vehicles reduces technical risks for future higher power systems, and builds up an industrial supply base that can reduce the cost of this class of mission. A retrofit (HDR) can be used to accomplish higher capability Mars missions while leveraging this industrial base, and/or these systems can be scaled up directly.

Demonstrated solar array and thruster technology can be scaled to the power levels needed for this entire suite of missions. Either solar array design-the Roll-Out Solar Array (ROSA) or MegaFlex-could work for any of the missions. The stowed volume packaging and deployed clearance are the factors that will determine which would be preferable for a given configuration. Specific impulses of 2000 to $3000 \mathrm{~s}$ have been experimentally verified and shown here to be sufficient for these missions. A high-voltage $(>120-\mathrm{V})$ power bus would substantially reduce the mass for $>400-\mathrm{kW}$ SEP systems by reducing wiring harness mass and enabling direct drive operation. Photovoltaic operation at this value has been experimentally demonstrated.

Adding a chemical propellant system to an SEP vehicle (forming a SEP-Chem hybrid) substantially reduces the trip time compared with SEP alone. Carrying both types of propulsion systems not only seems feasible from a mass, volume, and cost perspective, but it also provides a level of contingency operations that should increase the attractiveness of the concept. The required system power could be reduced by decreasing the mass of the largest payload, and by fueling in space.

\section{Acknowledgments}

We acknowledge the support of the Game Changing Technology Development and Technology Demonstration Mission Programs in NASA's Space Technology Mission Directorate, and the full capabilities of NASA Glenn's Collaborative Modeling for Parametric Assessment of Space Systems (COMPASS) team. Tom Percy, Melissa McGuire, and Tara Polsgrove performed the analysis for the concept described in Section IV.C. Gabe Merrill and Nathan Strange were the customers for the concept described in Section V.B.

\section{References}

1. Craig, D. A., Herrmann, N. B., and Troutman, P. A., “The Evolvable Mars Campaign - Study Status,” 2015 IEEE Aerospace Conference, Big Sky, MT, Mar. 7-14, 2015.

2. Williams, G., and Crusan, J., "Pioneering Space - the Evolvable Mars Campaign," presentation to the NASA Advisory Council, Washington DC, April 7-8, 2015. https:/www.nasa.gov/sites/default/files/files/20150408-NAC-Crusan-EMC-v7a.pdf

3. Manzella, D. H., and Hack, K., "High-Power Solar Electric Propulsion for Future NASA Missions,” AIAA 2014-3718, 50th AIAA/ASME/SAE/ASEE Joint Propulsion Conference, Cleveland, OH, July 28-30, 2014.

4. $\quad$ Mercer, C. R., Kerslake, T. W., Scheidegger, R. J., Woodworth, A. A., and Lauenstein, J.-M., "Solar Array Technology Development for Electric Propulsion,” 33rd Annual Space Power Workshop, Manhattan Beach, CA, May 2015.

5. Bobskill, M. R., Lupisella, M. L., Mueller, R. P., Sibille, L., Vangen, S., and Williams-Byrd, J., "Preparing for Mars: Evolvable Mars Campaign 'Proving Ground’ Approach,” 2015 IEEE Aerospace Conference, Big Sky, MT, Mar. 7-14, 2015.

6. McGuire, M. L., Hack, K. J., Manzella, D. H., and Herman, D. A., "Concept designs for NASA's Solar Electric Propulsion Technology Demonstration Mission,” AIAA 2014-3717, 50th AIAA/ASME/SAE/ASEE Joint Propulsion Conference, Cleveland, OH, July 28-30, 2014.

7. Landis, G. A., Oleson, S. R., and Mercer, C. R., "Solar Electric Propulsion for Future NASA Missions,” Photovoltaics Specialists Conference, New Orleans, LA, June 2015.

8. Sarver-Verhey, T. R., Kerslake, T. W., Rawlin, V. K., Falck, R. D., Dudzinski, L. J., and Oleson, S. R., "Solar Electric Propulsion Vehicle Design Study for Cargo Transfer to Earth-Moon L1," AIAA 2002-3971, 5th SAE Power Systems Conference, Society of Automotive Engineers, Coral Springs, FL, Oct. 29-31, 2002. Also NASA/TM-2002-211970. 
9. Hoffman, D. J., Kerslake, T. W., Hojnicki, J. S., Manzella, D. H., Falck, R. D., Cikanek III, H. A., Klem, M. D., and Free, J. M. "Concept Design of High Power Solar Electric Propulsion Vehicles for Human Exploration," NASA/TM-2011217281, IAC-11-D2.3.5.

10. Brophy, J. R., Gershman, R., Strange, N., Landau, D., Merrill, R. G., and Kerslake, T., "300-kW Solar Electric Propulsion System Configuration for Human Exploration of Near-Earth Asteroids," AIAA 2011-5514, 47th AIAA/ASME/SAE/ASEE Joint Propulsion Conference \& Exhibit, San Diego, CA, July 31-Aug. 3, 2011.

11. B.G. Drake, ed., "Human Exploration of Mars Design Reference Architecture 5.0,” NASA/SP_2009-566, July 2009.

12. Gates, M., Manzanek, D., Muirhead, B., Stich, S., Naasz, B., Chodas, P., McDonald, M., Reuter, J., "NASA’s Asteroid Redirect Mission Concept Development Summary,” 2015 IEEE Aerospace Conference, Big Sky, MT, Mar. 7-14, 2015.

13. Bobskill, M. R., and Lupisella, M. L., "The Role of Cis-Lunar Space in Future Global Space Exploration," GLEX2012.05.5.4x12270, NF-1676L-14657, Global Space Exploration Conference, May 22-24, 2012 Washington, DC, http://ntrs.nasa.gov/archive/nasa/casi.ntrs.nasa.gov/20120009459.pdf

14. Kerslake, T., "Advanced Solar Arrays for NASA Solar Electric Propulsion (SEP) Missions,” AIAA SciTech 2015 Spacecraft Structures Conference, Kissimmee, FL, Jan. 2015.

15. Mercer, C. R., Kerslake, T. W., Scheidegger, R. J., Woodworth, A. A., Lauenstein, J.-M., "Solar Array Technology Development for Electric Propulsion,” 33rd Annual Space Power Workshop, Manhattan Beach, CA, May 2015.

16. Herman, D. A., Santiago, W., Kamhawi, H., Polk, J. E., Snyder, J. S., Hofer, R. R., and Parker, J. M., “The Ion Propulsion System for the Solar Electric Propulsion Technology Demonstration Mission,” Joint Conference of 30th International Symposium on Space Technology and Science 34th International Electric Propulsion Conference and 6th Nano-satellite Symposium, Hyogo-Kobe, Japan, July 4-10, 2015.

17. Kamhawi, H., Huang, W., Haag, T., Yim, J., Chang, L., Clayman, L., Herman, D., Shastry, R., Thomas, R., Verhey, T., Griffith, C., Myers, J., Williams, G., Mikellides, I., Hofer, R., Polk, J., and Goebel, D., "Overview of the Development of the Solar Electric Propulsion Technology Demonstration Mission 12.5-kW Hall Thruster,” GRC-E-DAA-TN16633, 50th AIAA/ASME/SAE/ASEE Joint Propulsion Conference, Cleveland, OH, July 28-30, 2014.

18. Kamhawi, H., Huang, W., Haag, T., Shastry, R., Soulas, G., Smith, T., Mikellides, I., and Hofer, R., "Performance and Thermal Characterization of the NASA-300MS $20 \mathrm{~kW}$ Hall Effect Thruster,” IEPC-2013-444, 33rd International Electric Propulsion Conference, Washington, DC, Oct. 6-10, 2013.

19. NASA Glenn Research Center, "Space Flight Systems @ GRC, Space Science Projects Office, In-Space Propulsion Technologies Program: Suite Optimization Tools,” https://spaceflightsystems.grc.nasa.gov/SSPO/ISPTProg/LTTT/ Accessed June 22, 2015.

20. Brophy, J. R., and Oleson, S., "Spacecraft Conceptual Design for Returning Entire Near-Earth Asteroids," 48th AIAA/ASME/SAE/ASEE Joint Propulsion Conference, Atlanta, GA, July 29-Aug. 1, 2012.

21. NASA, "Bus Concepts to Support the Asteroid Redirect Robotic Mission and In-Space Robotic Servicing Spacecraft," Asteroid Redirect Mission Virtual Industry Day, May 22, 2015. http:/www.nasa.gov/sites/default/files/atoms/files/ 20150522-rfi-virtual-industry-day-charts-posted.pdf

22. Keck Institute for Space Studies, “Asteroid Retrieval Feasibility Study,” April 2, 2012.

23. Percy, T., McGuire, M., and Polsgrove, T., "Combining Solar Electric Propulsion and Chemical Propulsion for Crewed Missions to Mars,” 2015 IEEE Aerospace Conference, Big Sky, MT, Mar. 7-14, 2015.

24. NASA COMPASS team report, "HDR: High Delta-V Retrofit COMPASS Concept Design,” May 27, 2015.

25. Mercer, C. R., Oleson, S. R., Pencil, E. J., Piszczor, M. F., Mason, L. S., Bury, K. M., Manzella, D. H., Kerslake, T. W., Hojnicki, J. S., and Brophy, J. P., "Benefits of Power and Propulsion Technology for a Piloted Electric Vehicle to an Asteroid," Space 2011 Conference and Exposition, AIAA, Long Beach, CA, Sept. 27-29, 2011.

26. Capadona, L. A., Woytach, J. M., Kerslake, T. W., Manzella, D. H., Christie, R. J., Hickman, T. A., Scheidegger, R. J., Hoffman, D. J., and Klem, M. D., "Feasibility of Large High-Powered Solar Electric Propulsion Vehicles: Issues and Solutions," Space 2011 Conference and Exposition, AIAA, Long Beach, CA, Sept. 27-29, 2011.

27. Merrill, R., and Strange, N., "Mars Conjunction Crewed Missions with a Reusable Hybrid Architecture,” 2015 IEEE Aerospace Conference, Big Sky, MT, Mar. 7-14, 2015.

28. NASA GRC COMPASS team report, "Evolvable Mars Campaign: Hybrid SEP/Chemical Vehicle Designs Options 1 \& 2 Final Draft,” Internal report, Mar. 27, 2015.

29. Oleson, S. "Piloted Mars Combined SEPChem.: Conjunction Piloted and Cargo Designs," Future In-Space Operations (FISO) telecom, March 6, 2013. http://spirit.as.utexas.edu/ fiso/telecon/Oleson_3-6-13/ (Oleson_3-16-13.pdf) Accessed Aug. 3, 2015.

30. Oleson, S. R., Mercer, C. R., and Drake, B., “A Combined Solar Electric and Storable Chemical Propulsion Vehicle for Piloted Mars Missions,” AIAA 2013-xxxx, AIAA Space 2013 Conference, Long Beach CA, Sept. 2013. Also NASA/TM2012-217274.

31. Mercer, C. R., Oleson, S. R., and Drake, B. G., “Combined Solar Electric and Storable Chemical Propulsion,” Chapter 3.3, Human Exploration of Mars Design Reference Architecture 5.0 Addendum \#2, NASA/SP-2009-566-ADD2, B.G. Drake and K.D. Watts, eds., Mar. 2014. 